\title{
Research on Accelerating Single-Frequency Precise Point Positioning Convergence with Atmospheric Constraint
}

\author{
Ren Wang ${ }^{1,2}$, Jingxiang Gao ${ }^{1,2, *}$, Nanshan Zheng ${ }^{1,2, *}$, Zengke Li $^{1,2}$, Yifei Yao ${ }^{3}{ }^{\mathbb{C}}$, Long Zhao ${ }^{1,2}$ \\ and Yifan Wang ${ }^{1,2}$ \\ 1 NASG Key Laboratory of Land Environment and Disaster Monitoring, China University of Mining \\ and Technology, Xuzhou 221116, China; chwangr1990@cumt.edu.cn (R.W.); zengkeli@yeah.net (Z.L.); \\ cehuizl@126.com (L.Z.); cumtwangyf@163.com (Y.W.) \\ 2 School of Environment Science and Spatial Informatics, China University of Mining and Technology, \\ Xuzhou 221116, China \\ 3 College of Water Resources and Architectural Engineering, Northwest A\&F University, \\ Yangling 712100, China; yifeiyao@163.com \\ * Correspondence: jxgao@cumt.edu.cn (J.G.); znshcumt@163.com (N.Z.); Tel.: +86-135-0521-8387 (J.G.); \\ +86-159-5216-7986 (N.Z.)
}

Received: 23 November 2019; Accepted: 6 December 2019; Published: 10 December 2019

\begin{abstract}
An increasing number of researchers have conducted in-depth research on the advantages of low-cost single-frequency (SF) receivers, which can effectively use ionospheric information when compared to dual-frequency ionospheric-free combination. However, SF observations are bound to increase the unknown parameters and prolong the convergence time. It is desirable if the convergence time can be reduced by external information constraints, for example atmospheric constraints, which include ionosphere- or troposphere constraints. In this study, ionospheric delay constraints, tropospheric delay constraints, and their dual constraints were considered. Additionally, a total of 18,720 test experiments were performed. First, the nearest-neighbor extrapolation (NENE), bilinear(BILI), bicubic- (BICU), and Junkins weighted-interpolation (JUNK) method of Global Ionospheric Map (GIM) grid products were analyzed. The statistically verified BILI in the percentage of convergence time, average convergence time, and computation time consumption of them shows a good advantage. Next, the influences of global troposphere- and ionosphere-constrained on the convergence time of SF Precise Point Positioning (PPP) were analyzed. It is verified that the ionosphere-constrained (TIC2) has significant influence on the convergence time in the horizontal and vertical components, while the troposphere-constrained (TIC1) has better effect on the convergence time in the vertical components within some thresholds. Of course, the dual constraint (TIC3) has the shortest average convergence time, which is at least $46.5 \%$ shorter in static mode and $5.4 \%$ in kinematic mode than standard SF PPP (TIC0).
\end{abstract}

Keywords: single-frequency; interpolation; troposphere-constrained; ionosphere-constrained; precise point positioning; convergence time

\section{Introduction}

The concept and technology of Precise Point Positioning (PPP) were first proposed and implemented for the Global Positioning System (GPS) by the American Jet Propulsion Laboratory (JPL) in the late 1990s [1]. PPP has attracted significant interest over the intervening years due to its high accuracy without needing a specific reference station, providing correctional information, simple operations, and cost effectiveness due to reductions in labor and equipment costs. Therefore, it has been extensively used in the areas, 
for instance, determines the precise orbit, surface ice flow speed, as well as positioning, navigation and timing (PNT) applications [2-4]. The traditional PPP models are based on Ionosphere-Free (IF) combinations with dual-frequency raw phase and code observations for the removal of the first-order effect of ionospheric refraction [5]. However, the second- and third-order ionospheric effects still exist and they may cause measurements errors of sub-centimeters in GPS [6,7]. Therefore, traditional PPP technology based on IF combinations cannot obtain ionospheric information, and the ionospheric error is not completely eliminated. In the last few years, PPP used raw observations has received an increasing amount of research attention because of its several advantages as compared to traditional IF PPP, particularly the development of new multi-frequency GNSS [8].

The ionosphere refers to the atmospheric space starting at $60 \mathrm{~km}$ above the ground and extending to the magnetosphere. The Global Navigation Satellite System (GNSS) signal will generate ionospheric delay after passing through the ionosphere. A large number of models are currently being used to describe the delay that the ionosphere produces for electromagnetic signals propagating from satellites to receivers. If the delay is not corrected, it can have an important impact on the positioning accuracy of GNSS [9], especially for single-frequency PPP (SF PPP). Shi et al. proposed an improved method in which the deterministic representation is further refined by a stochastic process for each satellite with an empirical model for its power density [10]. The results of this method show that the singleand dual-frequency PPP exhibited enhanced convergence time, and the positioning accuracy of SF data is only improved by $25 \%$ [11]. Abd Rabbou et al. [12] developed an SF PPP model, and the improved model uses between-satellite-single-difference quasi-phase constrained GNSS observations. The GRoup and PHase Ionospheric Correction (GRAPHIC) method uses an SF code and carrier phase data to form an IF combined observation [13]. The positioning accuracy can reach several centimeters based on the GRAPHIC method, but the method requires two hours of convergence time [14].

The International GNSS Service (IGS) Ionosphere Working Group (IWG) was created in 1998. Several analysis centers (CODE (Center for Orbit Determination in Europe), ESA (European Space Agency), JPL (Jet Propulsion Laboratory), UPC (Universitat Politecnica de Catalunya), CAS (Chinese Academy of Sciences), and WHU (Wuhan University)) produce and release the post-processed Global Ionospheric Map (GIM) products, where the format is IONosphere EXchange (IONEX) $[15,16]$. The data portion of the GIM products utilized contain a total of 25 maps, with the latitude variation ranging from $87.5^{\circ}$ to $-87.5^{\circ}$ with an interval $-2.5^{\circ}$ and the longitude ranging from $-180^{\circ}$ to $180^{\circ}$ at $5^{\circ}$ intervals. The accuracy of the GIM is improved based on the Spherical Harmonic (SH) expansion model [17]. The VTEC of each ionospheric grid point is obtained while using different interpolation methods, such as bilinear interpolation [18], inverse distance weighted function [19], and Kriging interpolation [20]. Lanyi and Roth [21] proposed a polynomial model for single-station TEC derivation, and a single-station receiver bias can be estimated while using this model [22]. This method was used by Lu et al. [23] to study the effects of ionospheric shell height on GPS-based TEC derivation by a single station, while Kao et al. [24] applied this method to multi-stations. Chen et al. [25] analyzed the applicability of the sophisticated Klobuchar model for VTEC in China. Liu et al. [26] had based on GPS to observe and analyze the fluctuation characteristics of TEC over China.

In GNSS data processing, the slant tropospheric delay on the signal propagation path between the satellite and the receiver is usually mapped to the zenith direction via a mapping function. The Zenith Tropospheric Delay (ZTD) consists of the Zenith Hydrostatic Delay (ZHD) and the Zenith Wet Delay (ZWD, i.e., the zenith non-hydrostatic delay). The models of tropospheric delay estimation usually adopt the Hopfield model and Saastamoinen model. There are roughly two types of mapping functions. The first type are empirical models, which merely require the epoch time and the approximate coordinates of the receiver station, such as the Niell Mapping Function (NMF) [27] and the Global Mapping Function (GMF) [28]. The second type of mapping function is based on a large number of weather model analyses at the epoch of the observations, such as Isobaric Mapping Functions (IMF) [29] and Vienna Mapping Functions (VMF1) [28]. Huang et al. [30] proposes a new Asian single site tropospheric correction model, called the Single Site Improved European Geostationary Navigation Overlay Service model (SSIEGNOS). 
SF PPP cannot be combined or differenced to be eliminated or attenuated by a part of the error, like dual-frequency PPP. If there are some information related to the parameters, and this information is accurate enough, the precision of traditional SF PPP can be largely improved and the convergence time can be shortened. Zhang et al. [31] studied real-time GIM and its application in SF positioning, Aggrey and Bisnath [32] studied the effect of atmospheric-constrained on the convergence time of dual- and triple-frequency PPP, and Gao et al. [33] applied the Inertial Navigation System (INS) to the ionosphere-constrained PPP to overcome the drawbacks that accompany unexpected and unavoidable substandard observation environments.

This study uses the GIM products and the tropospheric zenith path delays from the IGS as the constrained information for SF PPP. The organization of this study is as follows: the next step details the methods for mathematical models of standard SF GPS PPP, troposphere-constrained SF GPS PPP, and ionosphere-constrained SF GPS PPP, and the details of the four interpolation methods of GIM products. Afterwards, in Section 3 we compare and analysis the influence of interpolation methods and constraint methods on SF GPS PPP convergence time, and finally in Section 4 we draw conclusions. Later, we will study ionospheric delay and tropospheric delay prediction models to provide virtual atmospheric delay observations for real-time PPP and also provide a priori information for the constraint processing.

\section{Methods}

The GPS PPP observation models are first derived. Afterwards, different interpolation methods for GIM products are introduced.

\subsection{GPS PPP Observation Models}

This study uses an undifferenced and uncombined GPS PPP model as compared with the traditionally used IF-PPP model. These models include a standard SF GPS PPP model, troposphere-constrained SF GPS PPP models, ionosphere-constrained SF GPS PPP models, and SF GPS PPP models with troposphere- and ionosphere-constrained.

\subsubsection{Standard Single-frequency GPS PPP Observation Model}

The distance from the satellite to the receiver can be measured while using pseudorange and carrier phase observations, with the following expression [34]:

$$
\left\{\begin{aligned}
P_{r}^{s} & =\rho_{r}^{s}+c \cdot\left(d t_{r}-d t^{s}\right)+I_{r}^{s}+M_{w} \cdot Z_{w}+M_{h} \cdot Z_{h}+d_{r}-d^{s}+\varepsilon_{r}^{s} \\
L_{r}^{s} & =\lambda_{1} \cdot \Phi_{r}^{s} \\
& =\rho_{r}^{s}+c \cdot\left(d t_{r}-d t^{s}\right)-I_{r}^{s}+M_{w} \cdot Z_{w}+M_{h} \cdot Z_{h}+\lambda_{1} \cdot\left(N_{r}^{s}+b_{r}-b^{s}\right)+\xi_{r}^{s} .
\end{aligned}\right.
$$

where, $P_{r}^{s}$ and $L_{r}^{s}$ are the original pseudorange and the carrier phase $\Phi_{r}^{s}$ is multiplied by wavelength $\lambda_{1}$ for the specific receiver $r$ and satellite $s ; \rho_{r}^{s}$ is the geometric distance from the satellite to the receiver; $\mathrm{c}$ is the speed of light in vacuum; $d t_{r}$ and $d t^{s}$ are the clock error of the receiver and satellite; $I_{r}^{s}$ is the slant ionospheric delay on the first frequency $\mathrm{f}_{1} ; M_{w}$ is the wet mapping function; $Z_{w}$ is the zenith wet delay; $M_{h}$ is the hydrostatic mapping function; $Z_{h}$ is the zenith hydrostatic delay; $d_{r}$ is the frequency-dependent receiver uncalibrated code delay (UCD) with respect to satellite $s ; d^{s}$ is the frequency-dependent satellite UCD; $N_{r}^{s}$ is the integer phase ambiguity; $b_{r}$ and $b^{s}$ are the uncalibrated phase delays (UPDs) for the receiver and satellite, which is frequency-dependent; and, $\varepsilon_{r}^{s}$ and $\xi_{r}^{s}$ are the sum of measurement noise caused by the pseudorange and carrier phase observations and the error caused by the multipath effect. Other errors have been modeled in advance.

The original pseudorange and carrier phase observations equations are linearized, and the receiver clock offset only absorbs common part of frequency dependent receiver UCDs. Supposing that $m$ 
satellites are tracked simultaneously at a certain epoch by the receiver $r$, the standard SF PPP model can be written, as follows [35]:

$$
\left[\begin{array}{c}
p_{r}^{1} \\
l_{r}^{1} \\
\vdots \\
p_{r}^{m} \\
l_{r}^{m}
\end{array}\right]=\left[\begin{array}{lllll}
-\mu_{r} & \boldsymbol{I}_{t} & M_{w} & \boldsymbol{K} & \boldsymbol{R}
\end{array}\right]\left[\begin{array}{c}
x \\
d \bar{t}_{r} \\
Z_{w} \\
\mathbf{I}_{r}^{s} \\
\overline{\boldsymbol{N}}_{r}^{s}
\end{array}\right]+\left[\begin{array}{c}
\varepsilon_{r} \\
\xi_{r}
\end{array}\right], \quad Q_{L},
$$

with

$$
\left\{\begin{array}{c}
d \bar{t}_{r}=d t_{r}+d_{r} \\
\bar{N}_{r}^{s}=\lambda_{1} \cdot\left(N_{r}^{s}+b_{r}-b^{s}\right)+d_{I F}^{s}-d_{r}
\end{array}\right.
$$

where $\boldsymbol{\mu}_{r}$ is the unit vector of the coordinate component between the receiver and the satellite; $x$ is the vector of the receiver position increments relative to the priori position; and, $\boldsymbol{I}_{t}$ is a unit vector of $2 \cdot \mathrm{m}$ rows and one column, corresponding to the receiver clock parameter $d \bar{t}_{r}$. In matrix $K$, the elements for the corresponding $p_{r}^{s}$ and $l_{r}^{s}$ are 1 and -1 , respectively, corresponding to the ionospheric parameter $\boldsymbol{I}_{r}^{s}$. $R$ is the matrix corresponding to the ambiguity parameters $\bar{N}_{r}^{s}$, and the elements for the corresponding $p_{r}^{s}$ and $l_{r}^{s}$ are 0 and 1 , respectively. $Q_{L}$ is the stochastic model of the observed minus computed (OMC) observables. IGS precise satellite clock was calculated by the IF combination observables and the IF combination of satellite UCDs was absorbed by the satellite clock offsets, as follows [2]:

$$
\begin{gathered}
d t_{I F_{12}}^{s}=d t^{s}+d_{I F_{12}}^{s} \\
d_{I F_{12}}^{s}=\alpha_{12} \cdot d_{1}^{s}+\beta_{12} \cdot d_{2}^{s}, \\
\alpha_{12}=\frac{\left(f_{1}^{s}\right)^{2}}{\left(\mathrm{f}_{1}^{\mathrm{s}}\right)^{2}-\left(\mathrm{f}_{2}^{\mathrm{s}}\right)^{2}}, \\
\beta_{12}=\frac{\left(\mathrm{f}_{2}^{\mathrm{s}}\right)^{2}}{\left(\mathrm{f}_{1}^{\mathrm{s}}\right)^{2}-\left(\mathrm{f}_{2}^{\mathrm{s}}\right)^{2}} .
\end{gathered}
$$

\subsubsection{Troposphere-Constrained Single-Frequency GPS PPP Observation Model}

According to the tropospheric delay product published by IGS, a virtual observation is used in the observation equation, and a troposphere-constrained SF GPS PPP is then constructed. The observation equation is expressed, as follows:

$$
\left[\begin{array}{c}
p_{r}^{1} \\
l_{r}^{1} \\
\vdots \\
p_{r}^{m} \\
l_{r}^{m} \\
\hat{T}_{r}
\end{array}\right]=\left[\begin{array}{ccccc}
-\boldsymbol{\mu}_{r} & \boldsymbol{I}_{t} & M_{w} & \boldsymbol{K} & \boldsymbol{R} \\
\mathbf{0} & \mathbf{0} & \boldsymbol{I}_{T} & \mathbf{0} & \mathbf{0}
\end{array}\right]\left[\begin{array}{c}
x \\
d \bar{t}_{r} \\
Z_{w} \\
\mathbf{I}_{r}^{1} \\
\overline{\boldsymbol{N}}_{r}^{s}
\end{array}\right]+\left[\begin{array}{c}
\varepsilon_{r} \\
\xi_{r} \\
\varepsilon_{r, \text { trop }}
\end{array}\right], \quad \boldsymbol{Q}_{L^{\prime}} \quad \boldsymbol{Q}_{T} .
$$

where $\boldsymbol{I}_{T}$ is a unit vector of $\mathrm{m}$ rows and one column, corresponding to the zenith wet delay parameter $Z_{w} ; \hat{T}_{r}$ is derived from external tropospheric products, the products for each IGS station at 5 min intervals provided by the IGS Analysis Center; $\varepsilon_{r, t r o p}$ is the corresponding noise; $Q_{T}$ denotes the stochastic model of virtual troposphere observables; and, $\mathbf{0}$ is a zero matrix. 


\subsubsection{Ionosphere-Constrained Single-Frequency GPS PPP Observation Model}

The ionosphere-constrained SF GPS PPP can add the GIM product as a virtual observation to constrain the ionospheric parameters as compared with the standard SF GPS PPP. The constraint equation for the observation is as follows [35]:

$$
\left[\begin{array}{c}
p_{r}^{1} \\
l_{r}^{1} \\
\vdots \\
p_{r}^{m} \\
l_{r}^{m} \\
\hat{\Lambda}^{1} \\
I_{r} \\
\vdots \\
\hat{\Lambda}^{m} \\
I_{r}
\end{array}\right]=\left[\begin{array}{ccccc}
-\mu_{r} & \boldsymbol{I}_{t} & M_{w} & \boldsymbol{K} & \boldsymbol{R} \\
\mathbf{0} & \mathbf{0} & \mathbf{0} & \mathbf{I}_{I} & \mathbf{0}
\end{array}\right]\left[\begin{array}{c}
\boldsymbol{x} \\
d \bar{t}_{r} \\
Z_{w} \\
\boldsymbol{I}_{r}^{1} \\
\overline{\boldsymbol{N}}_{r}^{s}
\end{array}\right]+\left[\begin{array}{c}
\varepsilon_{r} \\
\xi_{r} \\
\varepsilon_{r, i o n}
\end{array}\right], \quad \boldsymbol{Q}_{L^{\prime}} \quad \boldsymbol{Q}_{I}
$$

where $\hat{I}_{r}^{s}$ is derived from external ionospheric products with the corresponding noise $\varepsilon_{r, i o n} ; \boldsymbol{I}_{I}$ is a unit vector of $m$ rows and one column; and, $Q_{I}$ denotes the stochastic model of virtual ionospheric observables.

\subsubsection{Troposphere- and Ionosphere-Constrained Single-Frequency GPS PPP Observation Model}

If the external troposphere and ionospheric products are both used as virtual observations to constrain the observation equation, the following observation equation is obtained:

$$
\left[\begin{array}{c}
p_{r}^{1} \\
l_{r}^{1} \\
\vdots \\
p_{r}^{m} \\
l_{r}^{m} \\
\hat{T}_{r} \\
\hat{I}_{r}^{1} \\
\vdots \\
\hat{\Lambda}^{m} \\
I_{r}
\end{array}\right]=\left[\begin{array}{ccccc}
-\boldsymbol{\mu}_{r} & \boldsymbol{I}_{t} & M_{w} & \boldsymbol{K} & \boldsymbol{R} \\
\mathbf{0} & \mathbf{0} & \boldsymbol{I}_{T} & \mathbf{0} & \mathbf{0} \\
\mathbf{0} & \mathbf{0} & \mathbf{0} & \mathbf{I}_{I} & \mathbf{0}
\end{array}\right]\left[\begin{array}{c}
\boldsymbol{x} \\
d \bar{t}_{r} \\
Z_{w} \\
\boldsymbol{I}_{r}^{1} \\
\overline{\boldsymbol{N}}_{r}^{s}
\end{array}\right]+\left[\begin{array}{c}
\varepsilon_{r} \\
\xi_{r} \\
\varepsilon_{r, t r o p} \\
\varepsilon_{r, i o n}
\end{array}\right], \quad Q_{L}, \quad \boldsymbol{Q}_{T}, \quad Q_{I}
$$

\subsection{Different Interpolation Methods for GIM Products}

It is necessary to interpolate the ionospheric grid point from GIM products to obtain the observation station VTEC before performing the ionosphere-constrained modeling. In this study, a comparative analysis of four interpolation methods is performed. These methods include nearest-neighbor extrapolation [36], bilinear interpolation [18], Junkins weighted interpolation, and bicubic interpolation. The principles of the Junkins weighted and bicubic interpolation methods are described below.

\subsubsection{Junkins Weighted Interpolation}

Figure 1 shows the schematic of Junkins interpolation. In Figure 1, the latitude and longitude of the interpolation point are $b$ and $l$, that is, $p(b, l)$, and the values of the four GIM grid points adjacent to it are $p_{11}\left(b_{1}, l_{1}\right), p_{12}\left(b_{1}, l_{2}\right), p_{21}\left(b_{2}, l_{1}\right)$, and $p_{22}\left(b_{2}, l_{2}\right)$. It is assumed that the TEC values at $p_{11}, p_{12}, p_{21}$, and $p_{22}$ are $T E C_{11}, T E C_{12}, T E C_{21}$, and TEC 22 , respectively. The VTEC of point $p$ can be interpolated 
according to the VTEC of the surrounding four grid points. The interpolation formula used is as follows:

$$
f(b, l)=w_{1}(x, y) \cdot T E C_{11}+w_{2}(x, y) \cdot T E C_{12}+w_{3}(x, y) \cdot T E C_{21}+w_{4}(x, y) \cdot T E C_{22},
$$

The weighted function $w_{n}(x, y), n=1,2,3,4$ is as follows:

$$
\begin{gathered}
w_{1}(x, y)=\omega\left(1-x_{p}, 1-y_{p}\right), \\
w_{2}(x, y)=\omega\left(x_{p}, 1-y_{p}\right) \\
w_{3}(x, y)=\omega\left(x_{p}, y_{p}\right) \\
w_{4}(x, y)=\omega\left(1-x_{p}, y_{p}\right)
\end{gathered}
$$

where

$$
\begin{gathered}
\omega(A, B)=A^{2} B^{2}(9-6 A-6 B+4 A B), \\
x_{p}=\frac{l-l_{1}}{l_{2}-l_{1}}, \quad y_{p}=\frac{b-b_{1}}{b_{2}-b_{1}} .
\end{gathered}
$$

We can use nearest-neighbor extrapolation when the $p$ point only has two proximate GIM grid points.

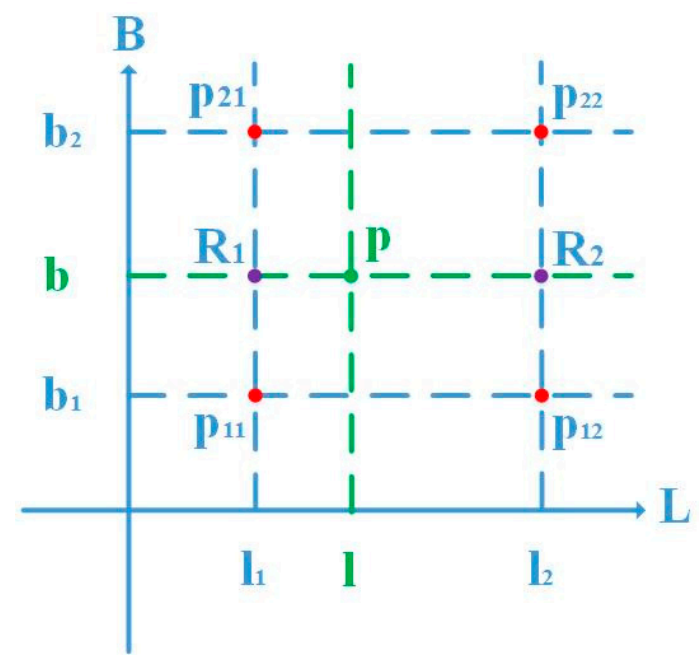

Figure 1. Schematic illustrating Junkins weighted interpolation.

\subsubsection{Bicubic Interpolation}

The bicubic interpolation [37] method uses 16 adjacent points for interpolation (Figure 2). Bicubic interpolation is an extension of cubic interpolation in a two-dimensional space. The cubic interpolation kernel is an approximation of the convolution interpolation of the ideal sampling sinc function at $[-2,2]$ that is based on the cubic polynomial [38]. Typically, cubic interpolation produces interpolation coefficients that are based on a third-order polynomial:

$$
h(q)=\left\{\begin{array}{cc}
1-(w+3)|q|^{2}+(w+2)|q|^{3}, & 0 \leq|q| \leq 1 \\
-4 w+8 w|q|-5 w|q|^{2}+w|q|^{3}, & 1 \leq|q| \leq 2 \\
0, & 2 \leq|q|
\end{array},\right.
$$


where $q$ represents the distance between the interpolation point and the reference point, $w$ is a tunable parameter, and the best result is obtained by verifying $w=-0.5$ [38] with a large amount of data. Under these conditions, Equation (18) is simplified to:

$$
h(q)=\left\{\begin{array}{cc}
1-2.5|q|^{2}+1.5|q|^{3}, & 0 \leq|q| \leq 1 \\
2-4|q|+2.5|q|^{2}-0.5|q|^{3}, & 1 \leq|q| \leq 2 \\
0, & 2 \leq|q|
\end{array}\right.
$$

Bicubic interpolation is similar to bilinear interpolation. It is also decomposed into two one-dimensional interpolations: horizontal interpolation and vertical interpolation. Figure 2 shows the interpolation process. First, vertical interpolation is performed to obtain four virtual values, and then the values of the $p$ point are obtained via interpolating based on the four virtual values. The calculation process is as follows:

$$
\left\{\begin{array}{l}
P_{1}=C_{1} P_{11}+C_{2} P_{21}+C_{3} P_{31}+C_{4} P_{41} \\
P_{2}=C_{1} P_{12}+C_{2} P_{22}+C_{3} P_{32}+C_{4} P_{42} \\
P_{3}=C_{1} P_{13}+C_{2} P_{23}+C_{3} P_{33}+C_{4} P_{43} \\
P_{4}=C_{1} P_{14}+C_{2} P_{24}+C_{3} P_{34}+C_{4} P_{44}
\end{array},\right.
$$

namely

$$
\begin{aligned}
& {\left[\begin{array}{llll}
P_{1} & P_{2} & P_{3} & P_{4}
\end{array}\right]=\left[\begin{array}{llll}
C_{1} & C_{2} & C_{3} & C_{4}
\end{array}\right]\left[\begin{array}{llll}
P_{11} & P_{12} & P_{13} & P_{14} \\
P_{21} & P_{22} & P_{23} & P_{24} \\
P_{31} & P_{32} & P_{33} & P_{34} \\
P_{41} & P_{42} & P_{43} & P_{44}
\end{array}\right], } \\
& F=L_{1} P_{1}+L_{2} P_{2}+L_{3} P_{3}+L_{4} P_{4} \\
&=\left[\begin{array}{llll}
P_{1} & P_{2} & P_{3} & P_{4}
\end{array}\right]\left[\begin{array}{l}
L_{1} \\
L_{2} \\
L_{3} \\
L_{4}
\end{array}\right] \\
&=\left[\begin{array}{llll}
C_{1} & C_{2} & C_{3} & C_{4}
\end{array}\right]\left[\begin{array}{llll}
P_{11} & P_{12} & P_{13} & P_{14} \\
P_{21} & P_{22} & P_{23} & P_{24} \\
P_{31} & P_{32} & P_{33} & P_{34} \\
P_{41} & P_{42} & P_{43} & P_{44}
\end{array}\right]\left[\begin{array}{l}
L_{1} \\
L_{2} \\
L_{3} \\
L_{4}
\end{array}\right],
\end{aligned}
$$

where

$$
\begin{gathered}
C_{1}=h\left(b-b_{1}\right), C_{2}=h\left(b-b_{2}\right), C_{3}=h\left(b_{3}-b\right), C_{4}=h\left(b_{4}-b\right) \\
L_{1}=h\left(l-l_{1}\right), L_{2}=h\left(l-l_{2}\right), L_{3}=h\left(l_{3}-l\right), L_{4}=h\left(l_{4}-l\right) \\
{\left[\begin{array}{lllll}
P_{11} & P_{12} & P_{13} & P_{14} \\
P_{21} & P_{22} & P_{23} & P_{24} \\
P_{31} & P_{32} & P_{33} & P_{34} \\
P_{41} & P_{42} & P_{43} & P_{44}
\end{array}\right]=\left[\begin{array}{llll}
T E C_{11} & T E C_{12} & T E C_{13} & T E C_{14} \\
T E C_{21} & T E C_{22} & T E C_{23} & T E C_{24} \\
T E C_{31} & T E C_{32} & T E C_{33} & T E C_{34} \\
T E C_{41} & T E C_{42} & T E C_{43} & T E C_{44}
\end{array}\right]}
\end{gathered}
$$

then

$$
f(b, l)=\left[\begin{array}{llll}
h\left(b-b_{1}\right) & h\left(b-b_{2}\right) & h\left(b_{3}-b\right) & h\left(b_{4}-b\right)
\end{array}\right]\left[\begin{array}{llll}
T E C_{11} & T E C_{12} & T E C_{13} & T E C_{14} \\
T E C_{21} & T E C_{22} & T E C_{23} & T E C_{24} \\
T E C_{31} & T E C_{32} & T E C_{33} & T E C_{34} \\
T E C_{41} & T E C_{42} & T E C_{43} & T E C_{44}
\end{array}\right]\left[\begin{array}{l}
h\left(l-l_{1}\right) \\
h\left(l-l_{2}\right) \\
h\left(l_{3}-l\right) \\
h\left(l_{4}-l\right)
\end{array}\right] .
$$




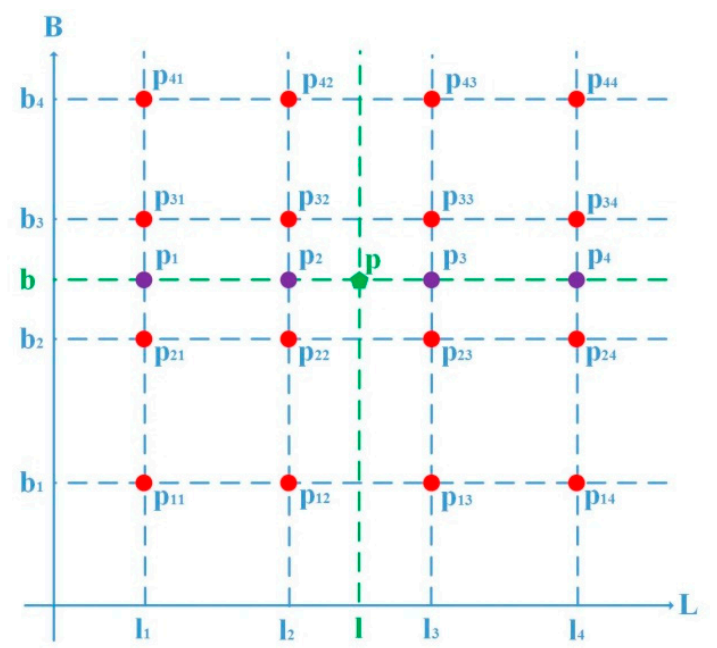

Figure 2. Schematic illustrating Bicubic interpolation.

We can use bilinear interpolation when the number of GIM grid points around point $p$ is less than 16.

Tropospheric delay interpolation is similar to inverse distance-weighted interpolation [19], and it is performed according to the relationship between the tropospheric delay value and time in the tropospheric products.

\section{Experimental Data Set and Analysis}

The PPP results based on raw observations are evaluated with 78 global IGS stations for the whole month of September 2017 to verify the improved troposphere- and ionosphere-constrained for GPS SF PPP performance. For every station, the 24-h observations were divided into eight 3-h sessions to evaluate the performance of PPP. Therefore, a total of 18720 experiments were tested and compared. Figure 3 shows the distribution of these stations in the world. Figure 4 show a flowchart of our study procedure, while Table 1 lists the models and strategies that were used in this study.

The PPP performance in terms of convergence time in the horizontal and vertical components is evaluated at a different confidence level (the 68\% and 95\%) in two modes (static and kinematic). The criterion for judging convergence is when the positioning error in the horizontal and vertical components is less than $0.5 \mathrm{~m}$ (95\% level) and $0.3 \mathrm{~m}$ (68\% level), respectively [11].

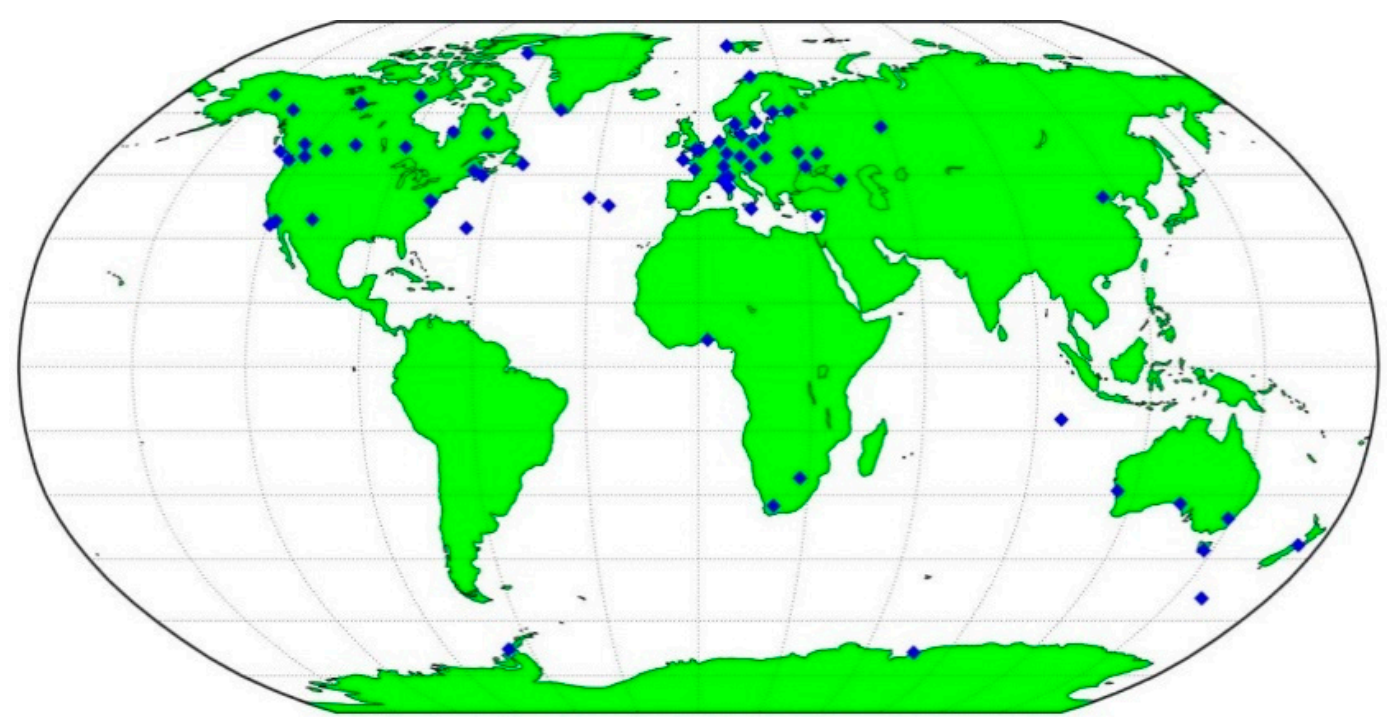

Figure 3. Geographical distribution of the selected 78 global IGS tracking stations. 


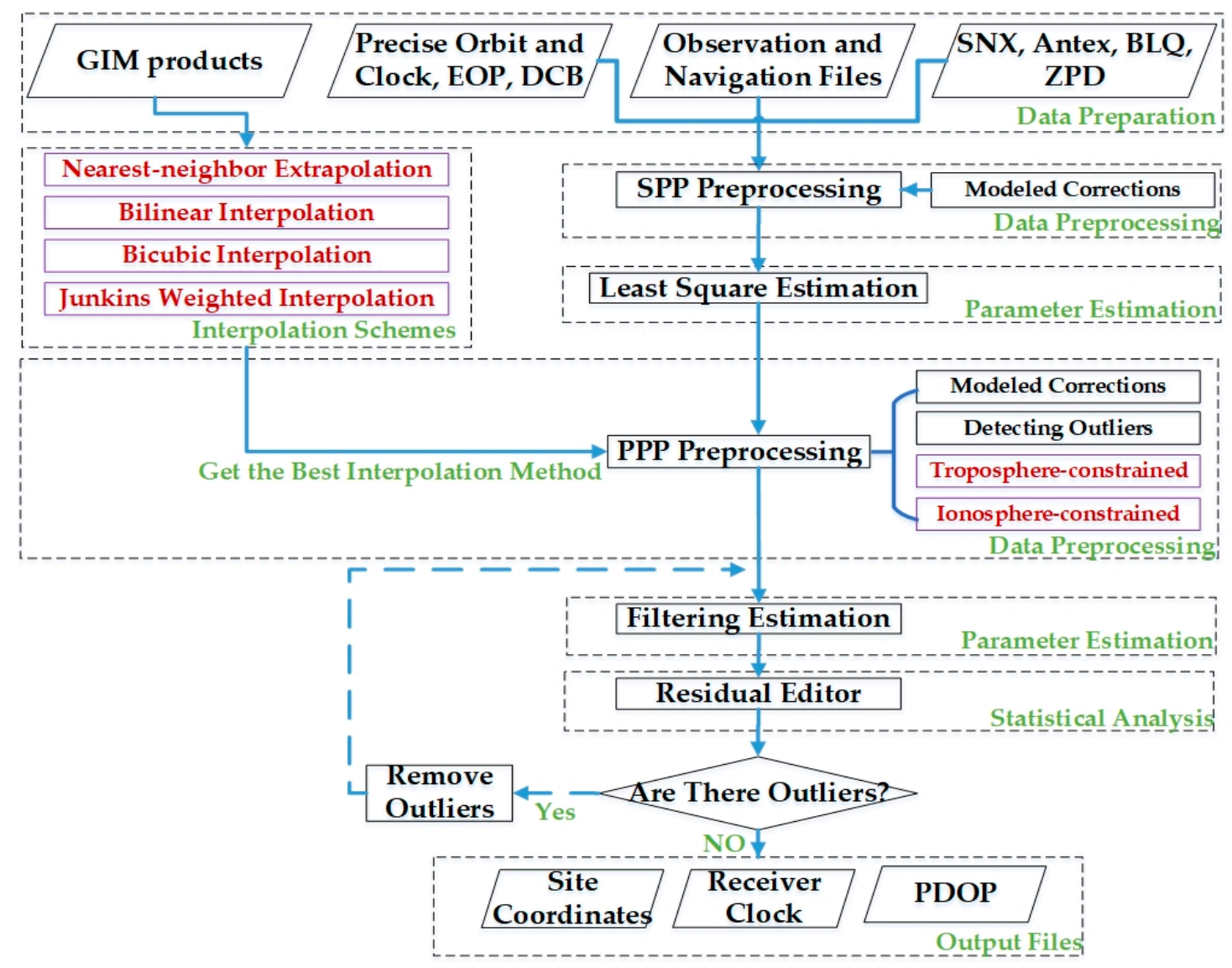

Figure 4. The flowchart of our study procedure.

Table 1. Models and strategies used in single-frequency Precise Point Positioning (SF PPP).

\begin{tabular}{cc}
\hline Item. & Models/Strategies \\
\hline Constellation & GPS \\
Data span & 1-30 Sep 2017 \\
Observations & L1 \\
Frequency selection & $30 \mathrm{~s}$ \\
Sampling rate & $7^{\circ}$ \\
Satellite cut-off elevation & GPS raw code and phase observations \\
Positioning mode & Final by IGS orbit and clock products \\
Estimator & Kalman filter \\
Satellite orbit and clock & A priori precision of 0.003 and 0.3 m for raw phase and code [35] \\
Weighing strategy & Correct using CODE Differential Code Bias (DCB) products \\
Satellite DCB & Klobuchar model [39] (priori) or GIM products from IGS (constrains) \\
Ionospheric delay & Random walk [10] \\
Ionospheric noise & Saastamoinen model [40] (priori) or products from IGS (constrains) \\
Tropospheric delay & Solid Earth, pole and ocean tide were corrected [41] \\
Tide displacement & Corrected model [42] \\
Sagnac effect & Corrected model [43] \\
Relativistic effect & IGS SINEX files \\
Satellite and receiver antenna & Phase Center Offset (PCO) and Variations (PCVs) values from igs14.atx \\
Reference coordinates & Float values \\
Phase ambiguities &
\end{tabular}

\subsection{The Effect of Interpolation Method on Ionosphere-constrained GPS Single-frequency PPP}

For the convenience of description, Table 2 shows the abbreviations, according to the four interpolation methods that were introduced above. For GIM grid products, this study discuss the 
convergence time of the four interpolation methods under ionosphere-constrained and the average time of calculation of 78 stations.

Table 2. The four interpolation schemes.

\begin{tabular}{cccc}
\hline Abbreviation & Item & Abbreviation & Item \\
\hline NENE & Nearest-neighbor extrapolation & BILI & Bilinear interpolation \\
BICU & Bicubic interpolation & JUNK & Junkins weighted interpolation \\
\hline
\end{tabular}

Figures 5 and 6 show the percentage of convergence time. From these two pictures, whether in the $95 \%$ or $68 \%$ level, and whether it is static mode or kinematic mode, the convergence time is less than $10 \mathrm{~min}$, the percentage of the BILI method calculation result is slightly lower than the other three methods, and in the subsequent convergence time less than $20 \mathrm{~min}, 30 \mathrm{~min}$, etc., the percentage of BILI method calculation results has been higher than the other three methods, as shown in the green histogram. That is to say, the convergence time of the BILI interpolation method is the shortest when compared to the other three methods. Figure 7 shows the statistical results of the root mean square (RMS) error in the horizontal and vertical components in the static and kinematic mode, respectively. The RMS errors are based on the statistics of the last $15 \mathrm{~min}$ of the position solution error [44]. In the static mode, the percentage of BILI method calculations exceeds $40 \%$ in the horizontal and vertical components when the RMS is less than $5 \mathrm{~cm}$, and the other three methods are lower than $40 \%$ and, in the subsequent statistical stages, the percentage of the BILI method is higher than the other three methods to reach $100 \%$. In the kinematic mode, the percentage of BILI method calculation results in the horizontal component is $60 \%$ when the RMS is less than $15 \mathrm{~cm}$, and the other three methods are lower than this value; while, in the vertical component, the BILI method exceeds $40 \%$, and the other three methods not reaching $40 \%$, and the percentage of BILI methods in other statistical stages is higher than the other three methods. In summary, the BILI method has higher final positioning accuracy than the other three methods in both the static and kinematic modes in the horizontal or vertical component.

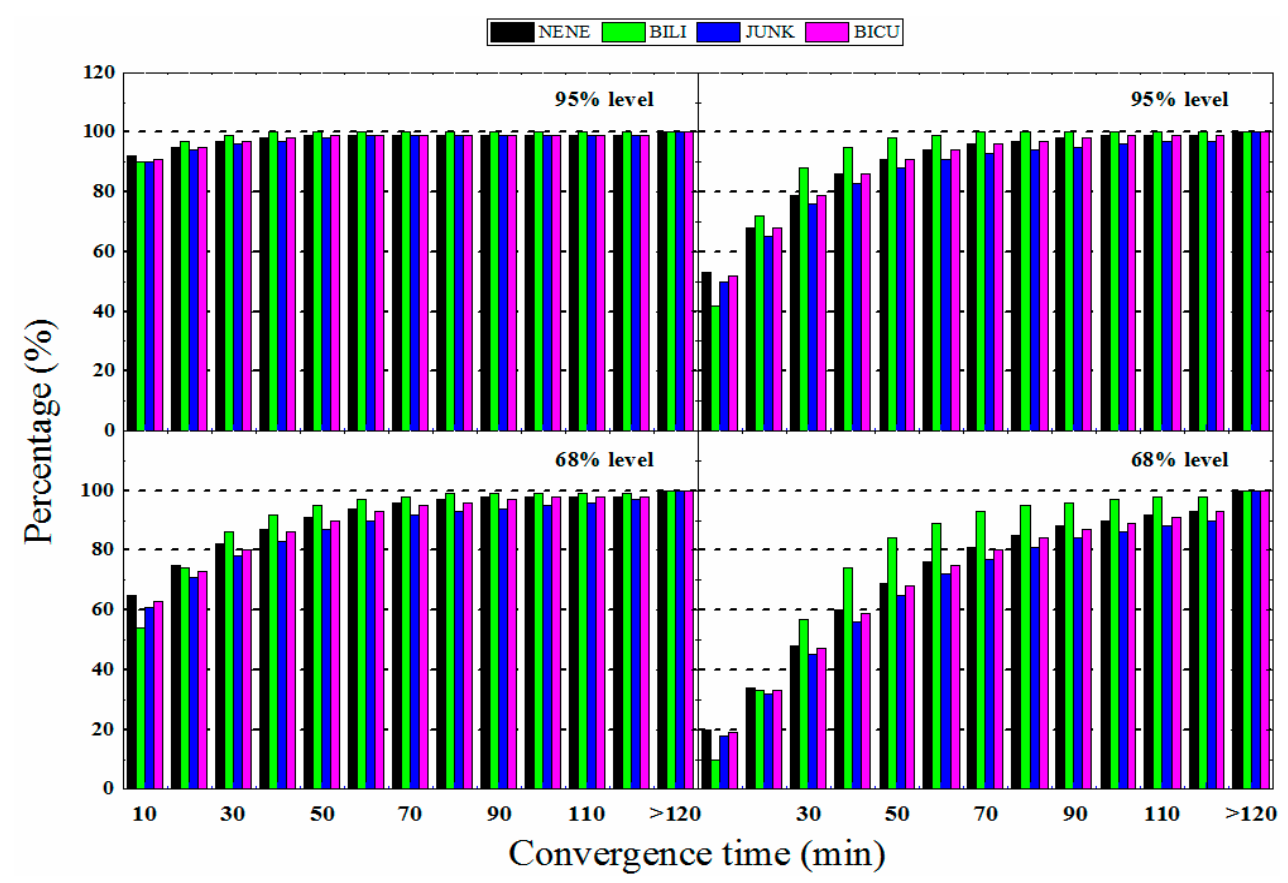

Figure 5. The percentage of Global Positioning System (GPS) SF PPP convergence time in different interpolation schemes in the static mode (horizontal component (left panel) and vertical component (right panel)). 


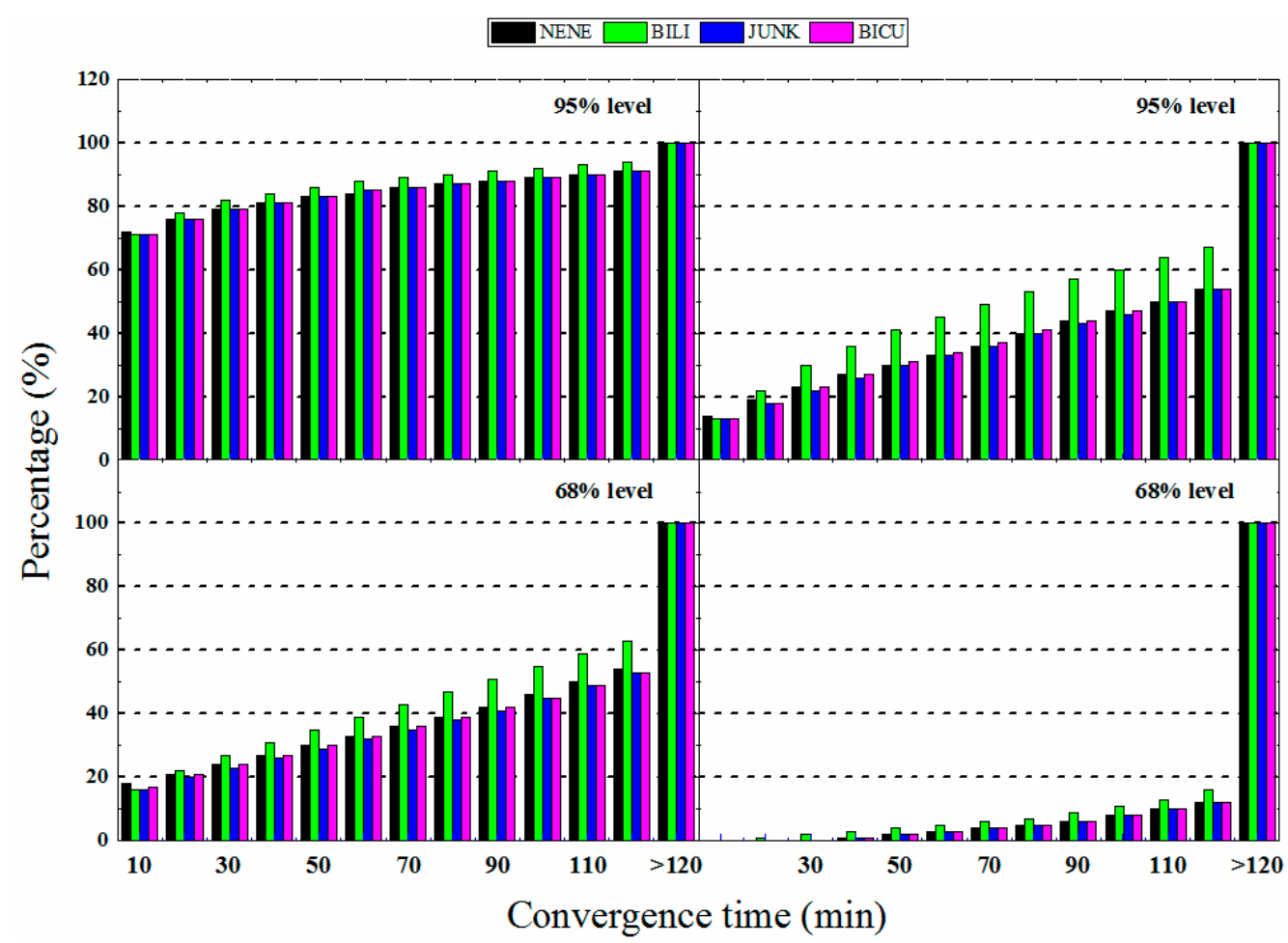

Figure 6. The percentage of GPS SF PPP convergence time in different interpolation schemes in the kinematic mode (horizontal component (left panel) and vertical component (right panel)).

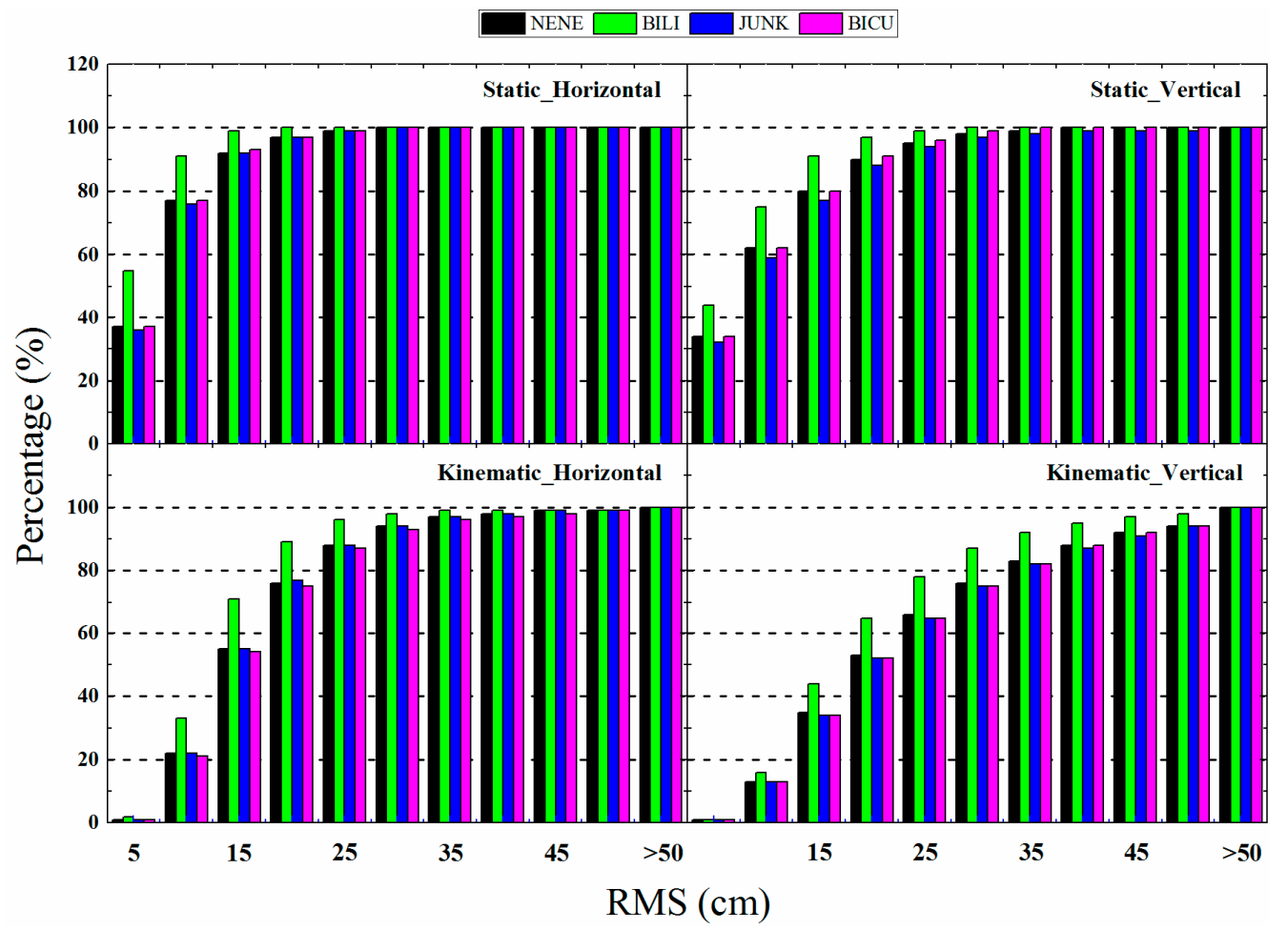

Figure 7. The percentage of GPS SF PPP root mean square (RMS) in different ranges in the static and kinematic mode.

The average convergence time (removed the data that the convergence time is equal to $180 \mathrm{~min}$, that is, the data that does not convergence within three hours) is shown in Table 3, as compared to the JUNK method with the longest average convergence time, the average convergence time of BILI method 
at the $95 \%$ level is improved from 3.87 to $3.14 \mathrm{~min}(18.9 \%)$ in horizontal $(\mathrm{H}(95 \%))$ and by from 19.44 to $15.18 \mathrm{~min}(21.9 \%)$ in the vertical components $(\mathrm{V}(95 \%))$ in the static mode, while, in the kinematic mode, it increased by $15.3 \%$ in the horizontal component and $13.2 \%$ in the vertical component. At the $68 \%$ level, the average convergence time in the horizontal component $(\mathrm{H}(68 \%))$ significantly reduced by $17.9 \%$ from 17.55 to $14.40 \mathrm{~min}$ and by $23.6 \%$ from 42.92 to $32.81 \mathrm{~min}$ in the vertical component $(\mathrm{V}(68 \%))$ in the static mode, and in the kinematic mode, lessened by $6.8 \%$ and $2.3 \%$ in the horizontal component and vertical component, respectively. The calculation time of these 18720 tests was normalized to FLRS station (Table 4). We used a Lenovo computer, which is configured with Windows 8.1 professional computer with an i5-3470 Central Processing Unit (CPU) and 4GB of installed Random Access Memory (RAM). From Table 4, it can be concluded that the BILI interpolation method calculation time is almost the same as the Junkins weighted interpolation method, which takes the shortest time. According to all of the above analysis, the interpolation method that is adopted for GIM products in the following ionosphere-constrained model is bilinear interpolation.

Table 3. Average convergence time of GPS static and kinematic SF PPP in different interpolation schemes.

\begin{tabular}{ccccccccc}
\hline \multirow{2}{*}{ Scheme } & \multicolumn{3}{c}{ Static SF PPP (min) } & \multicolumn{3}{c}{ Kinematic SF PPP (min) } \\
\cline { 2 - 9 } & $\mathbf{H ( 9 5 \% )}$ & $\mathbf{H ( 6 8 \% )}$ & $\mathbf{V ( 9 5 \% )}$ & $\mathbf{V ( 6 8 \% )}$ & $\mathbf{H ( 9 5 \% )}$ & $\mathbf{H ( 6 8 \% )}$ & V(95\%) & V(68\%) \\
\hline NENE & 3.21 & 15.10 & 17.20 & 40.60 & 18.45 & 77.34 & 78.46 & 134.10 \\
BILI & 3.14 & 14.40 & 15.18 & 32.81 & 16.10 & 73.00 & 68.95 & 131.50 \\
JUNK & 3.87 & 17.55 & 19.44 & 42.92 & 19.00 & 78.30 & 79.44 & 134.60 \\
BICU & 3.42 & 15.70 & 17.68 & 41.30 & 19.30 & 78.30 & 79.01 & 134.30 \\
\hline
\end{tabular}

Table 4. Calculation time of FLRS station in SF PPP in different interpolation schemes.

\begin{tabular}{ccc}
\hline Interpolation Method & Static (sec) & Kinematic (sec) \\
\hline NENE & 6.905 & 6.821 \\
BILI & 6.550 & 6.512 \\
BICU & 6.775 & 6.797 \\
JUNK & 6.429 & 6.474 \\
\hline
\end{tabular}

\subsection{Single-Frequency PPP with the Constraints}

In this section, we analyse the effects of single-frequency GPS on unconstrained, troposphereconstrained, ionosphere-constrained, and their dual constrains on convergence time. Table 5 summarizes the four constraint schemes.

Table 5. The four constraint schemes.

\begin{tabular}{cc}
\hline Abbreviation & Item \\
\hline TIC0 & Standard single-frequency PPP model \\
TIC1 & Troposphere-constrained single-frequency PPP model \\
TIC2 & Ionosphere-constrained single-frequency PPP model \\
TIC3 & Troposphere- and ionosphere-constrained single-frequency PPP model \\
\hline
\end{tabular}

Figures 8 and 9 show the percentage statistics of the effects of different constraint methods on the convergence time of GPS. It can be concluded from these two figures that in the horizontal component, the convergence time of the TIC 3 has the largest percentage in the same range, and the TIC1 has less influence on the convergence time. In the vertical component, the percentage of convergence time of the TIC 3 in the same range is still the largest, but the influence of TIC1 on the convergence time is higher than the percentage of TIC2 in a certain range. On the whole, the convergence performance of TIC0 is worse in both components when not using GIM products or tropospheric products as constraints. The convergence performance is improved as compared to TIC 0 after considering TIC1 or (and) TIC2 in GPS SF PPP processing. 


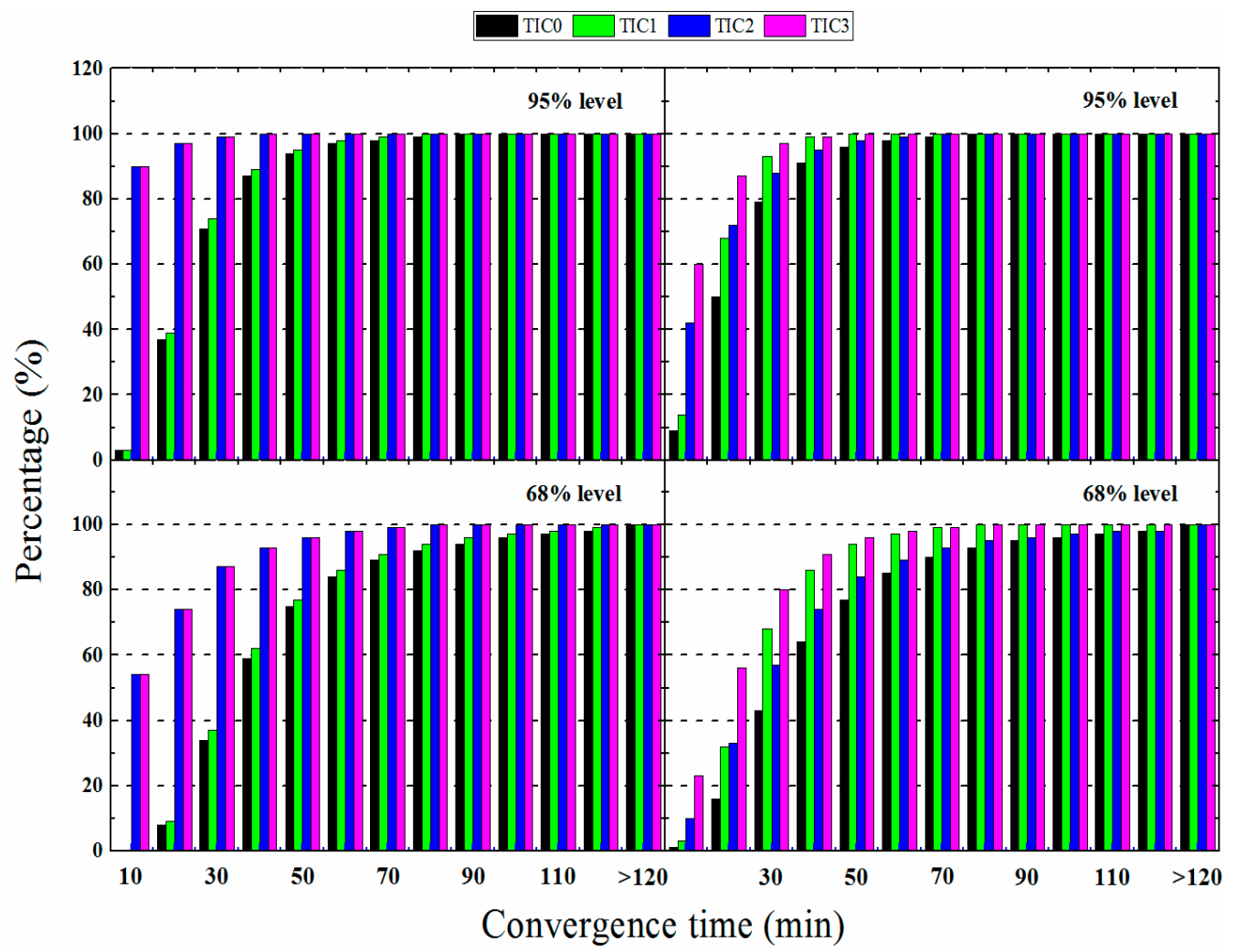

Figure 8. The percentage of GPS static SF PPP convergence performance in different constrain schemes (horizontal component (left panel) and vertical component (right panel)).

\begin{tabular}{|l|l}
\hline TIC0 $\square$ TIC1 $\square$ TIC2 $\square$ TIC3 \\
\hline
\end{tabular}

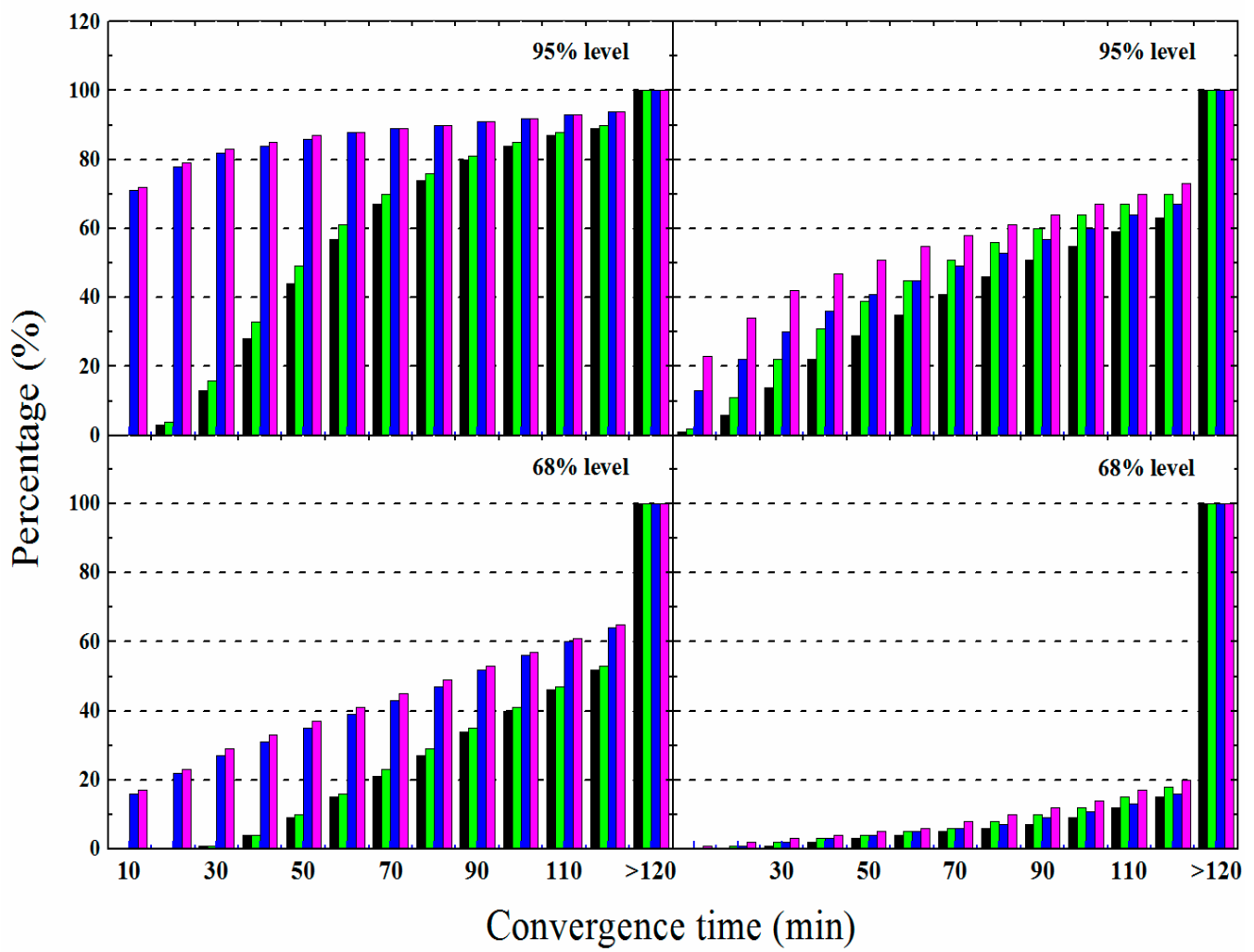

Figure 9. The percentage of GPS kinematic SF PPP convergence performance in different constrain schemes (horizontal component (left panel) and vertical component (right panel)). 
At the same time, Table 6 shows that TIC 1 performs a notably better than TIC 0 in the vertical component and marginally better than TIC0 in the horizontal component. TIC2 performs notably better than TIC 0 and TIC1 in the horizontal component, while, in the vertical component, TIC2 is better than TIC 0 and worse than TIC1 only in $68 \%$ level static mode. TIC 3 performs best among the handling schemes. Compared with TIC0, the average convergence time of TIC1 at the $95 \%$ level is improved from 27.17 to $26.07 \mathrm{~min}(4.0 \%)$ in horizontal and by from 23.21 to $18.17 \mathrm{~min}(21.7 \%)$ in the vertical components. At the $68 \%$ level, the convergence time in the horizontal component reduced by $4.3 \%$ from 42.11 to $40.29 \mathrm{~min}$ and by $28.8 \%$ from 39.34 to $27.98 \mathrm{~min}$ in the vertical component. However, in kinematic mode, the average convergence time of TIC1 is not much higher than that of TIC0, with a maximum increase of $11.7 \%$ and a minimum increase of $2.1 \%$. TIC2 has a larger boost when compared with TIC 0 . In static mode, it is increased by $16.6 \%$ in the vertical component by $68 \%$ level, and the maximum increase is $88.4 \%$ in the horizontal component of $95 \%$ level; in kinematic mode, they are $2.5 \%$ and $73.9 \%$, respectively. TIC3 has the largest boost as compared with the other two methods. In static mode, it reaches $88.8 \%$ from 27.17 to $3.04 \mathrm{~min}$ and the lowest is $46.5 \%$ from 39.34 to $21.05 \mathrm{~min}$ In the kinematic mode, the minimum increase is $5.4 \%$, and the maximum increase is $74.5 \%$.

Three stations (FLRS, TRO1, and ZECK station) were randomly selected from 78 IGS stations to measure RMS error in the horizontal component, vertical component, and three-dimensional. It can be seen from Figures 10 and 11 that the final positioning error reaches the sub-decimetre level in the kinematic mode, and it reaches the centimetre level in the static mode. However, the final positioning errors are substantially close in the four schemes.

Table 6. Average convergence time of GPS static and kinematic SF PPP in different constrained schemes.

\begin{tabular}{ccccccccc}
\hline \multirow{2}{*}{ Scheme } & \multicolumn{3}{c}{ Static SF PPP (min) } & \multicolumn{3}{c}{ Kinematic SF PPP (min) } \\
\cline { 2 - 9 } & $\mathbf{H ( 9 5 \% )}$ & $\mathbf{H ( 6 8 \% )}$ & $\mathbf{V ( 9 5 \% )}$ & $\mathbf{V ( 6 8 \% )}$ & $\mathbf{H ( 9 5 \% )}$ & $\mathbf{H ( 6 8 \% )}$ & V(95\%) & V(68\%) \\
\hline TIC0 & 27.17 & 42.11 & 23.21 & 39.34 & 61.63 & 103.07 & 81.84 & 134.81 \\
TIC1 & 26.07 & 40.29 & 18.17 & 27.98 & 58.99 & 100.90 & 72.28 & 131.58 \\
TIC2 & 3.15 & 14.39 & 15.18 & 32.82 & 16.06 & 73.29 & 69.01 & 131.40 \\
TIC3 & 3.04 & 14.08 & 9.57 & 21.05 & 15.70 & 71.53 & 57.41 & 127.59 \\
\hline
\end{tabular}
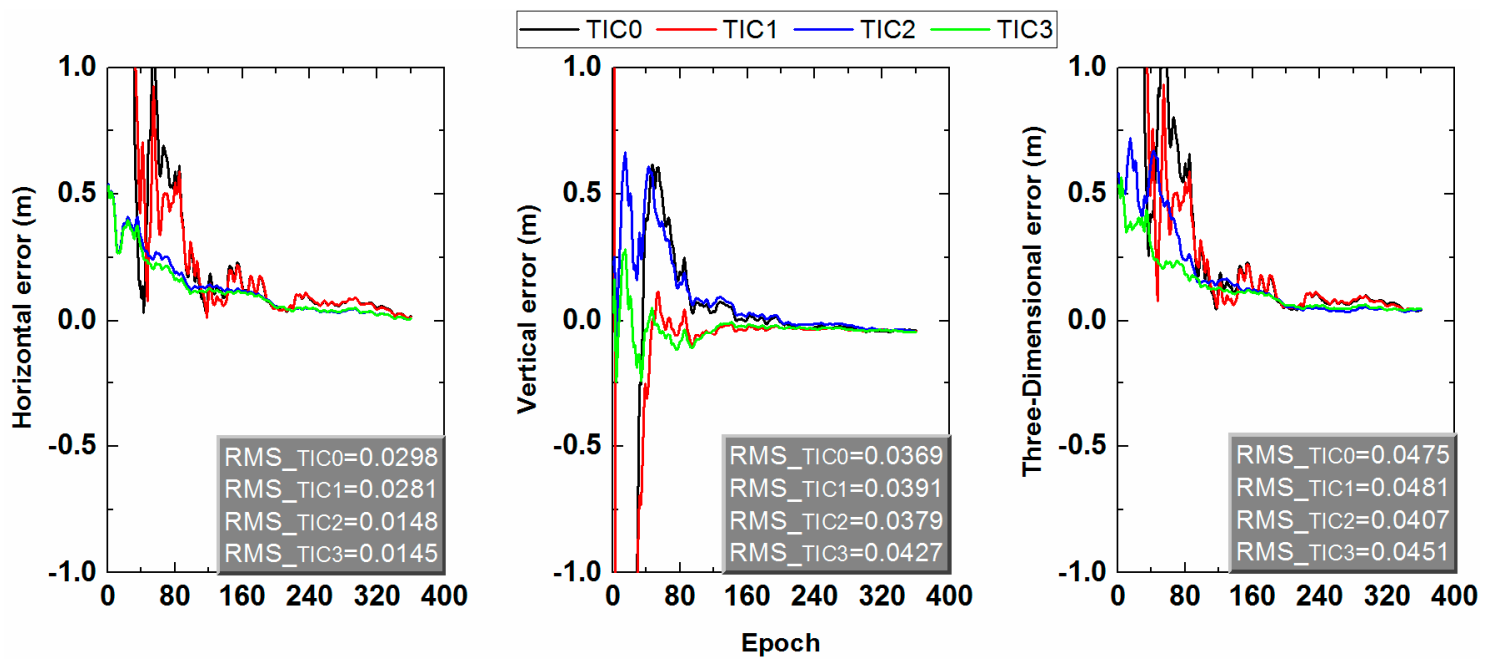

(a) FLRS Station (11 September 2017 18:00:00-20:59:30)

Figure 10. Cont. 

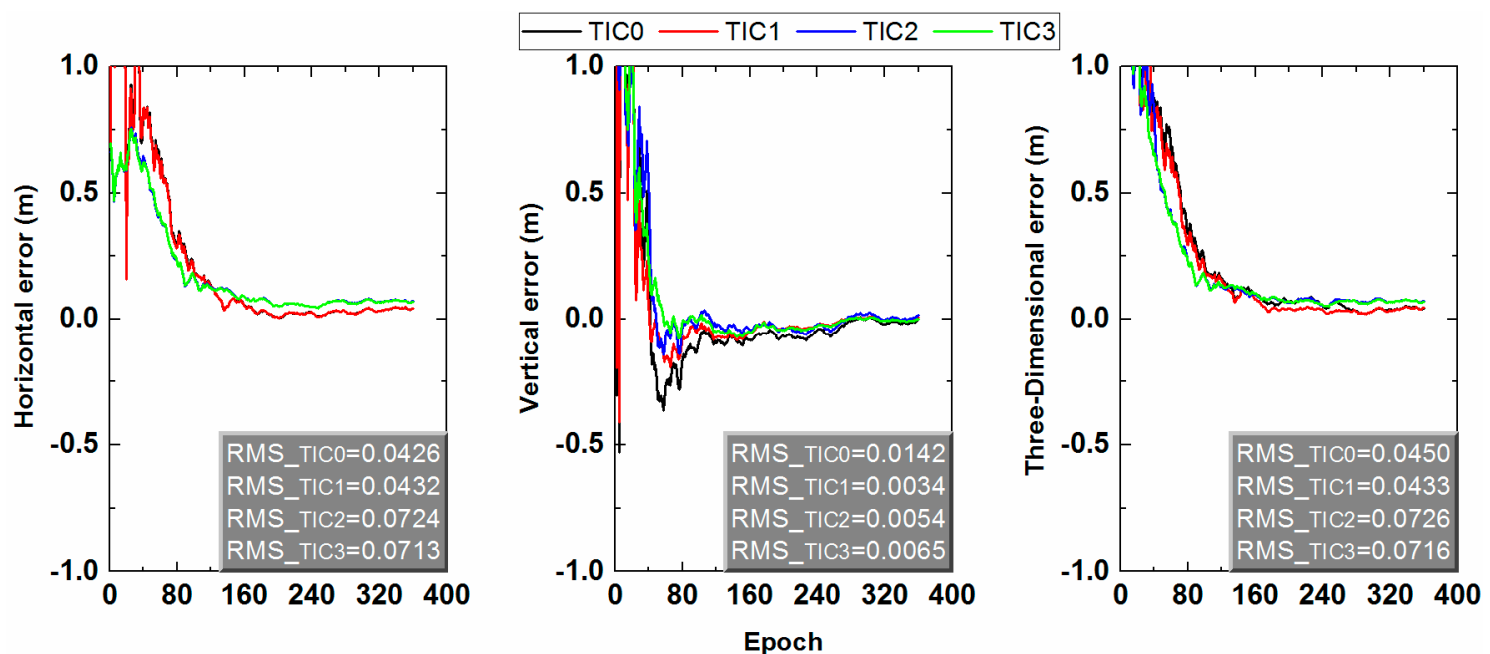

(b) TRO1 Station (21 September 2017 12:00:00-14:59:30)
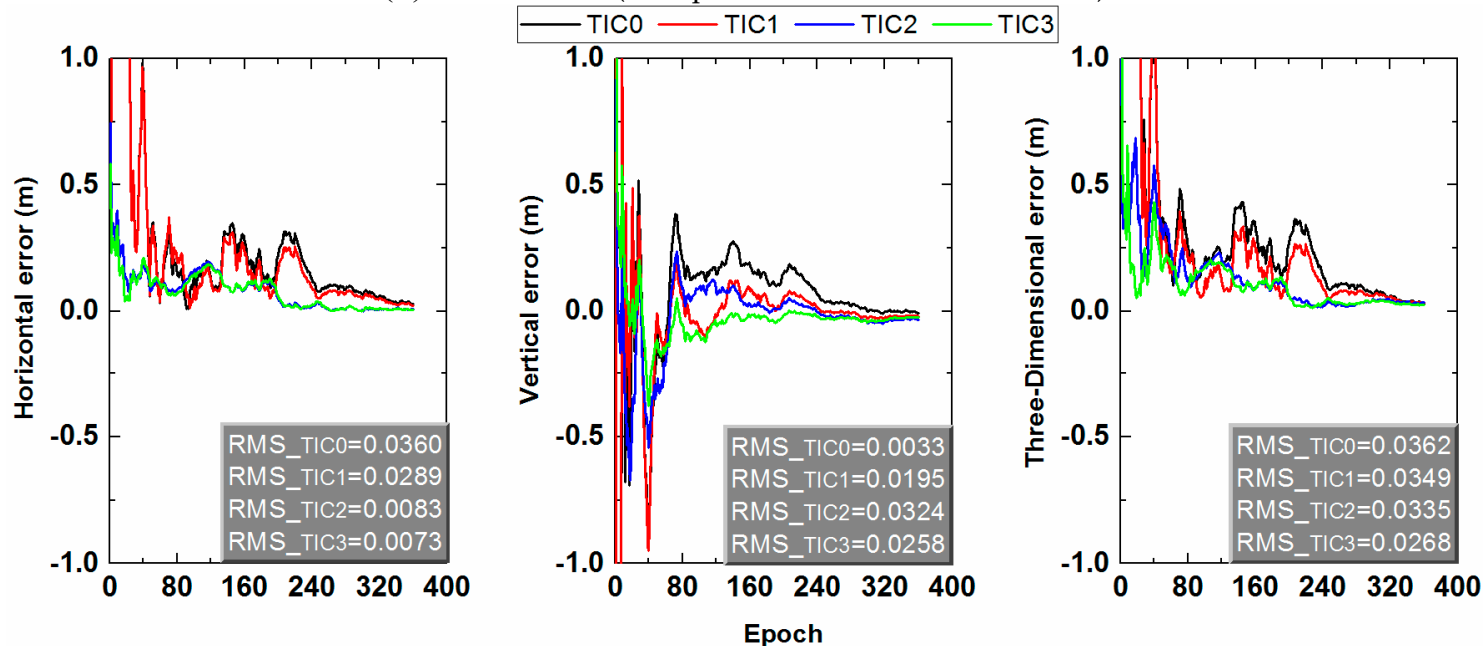

(c) ZECK Station (30 September 2017 3:00:00-5:59:30)

Figure 10. (a) FLRS station, (b) TRO1 station, and (c) ZECK station SF PPP coordinate deviation RMS statistics in static mode.
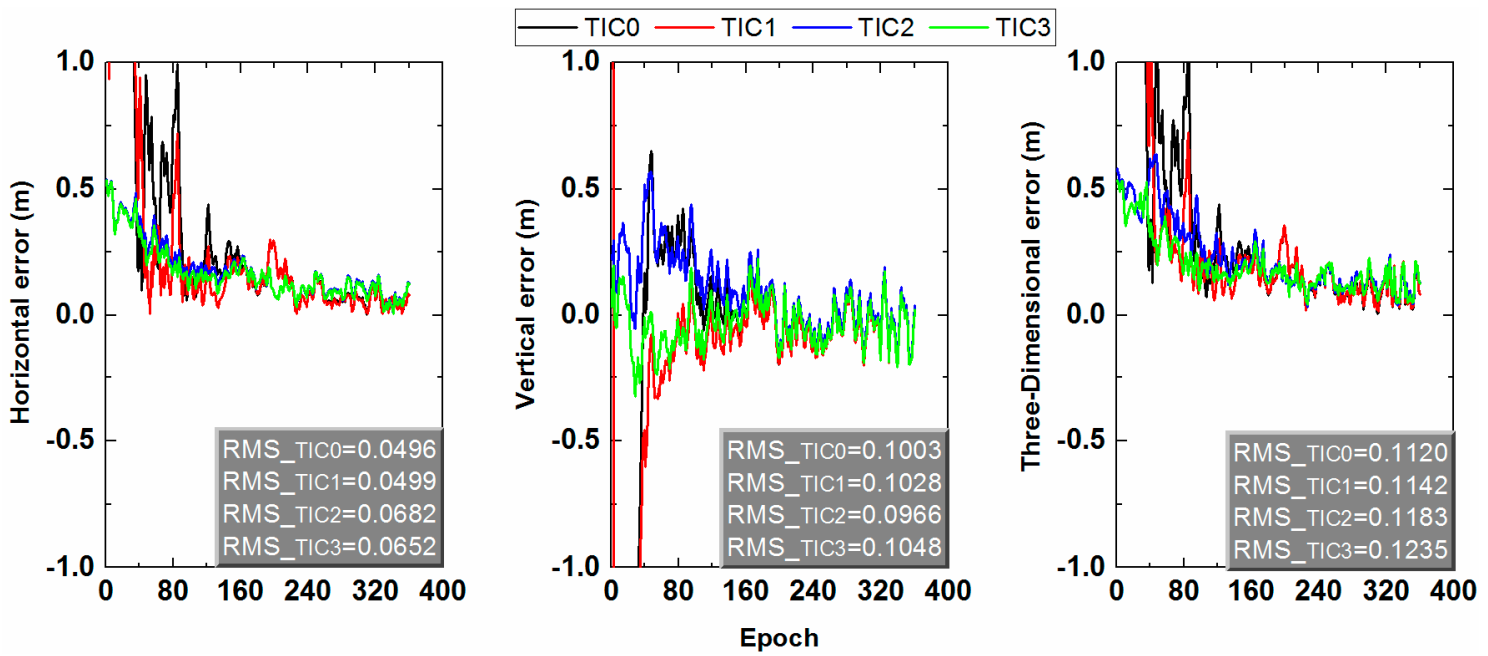

(a) FLRS Station (11 September 2017 18:00:00-20:59:30)

Figure 11. Cont. 

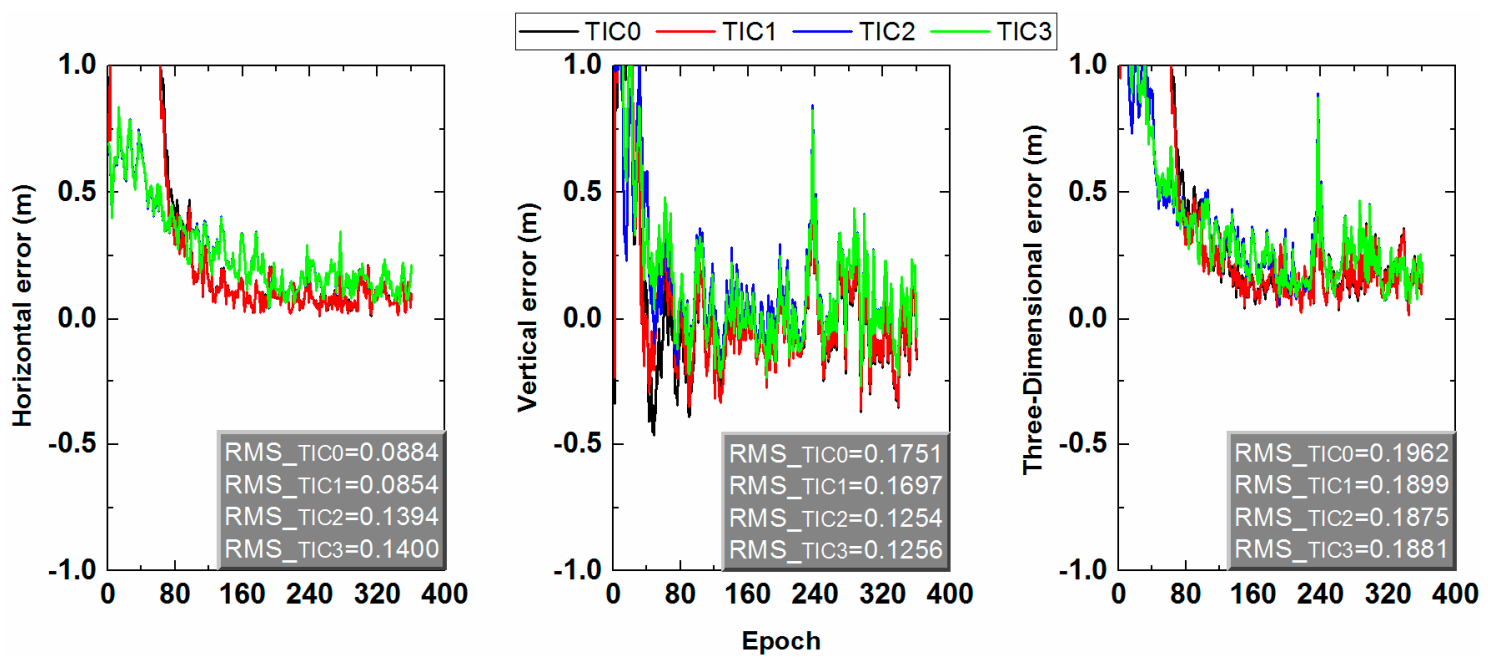

(b) TRO1 Station (21 September 2017 12:00:00-14:59:30)
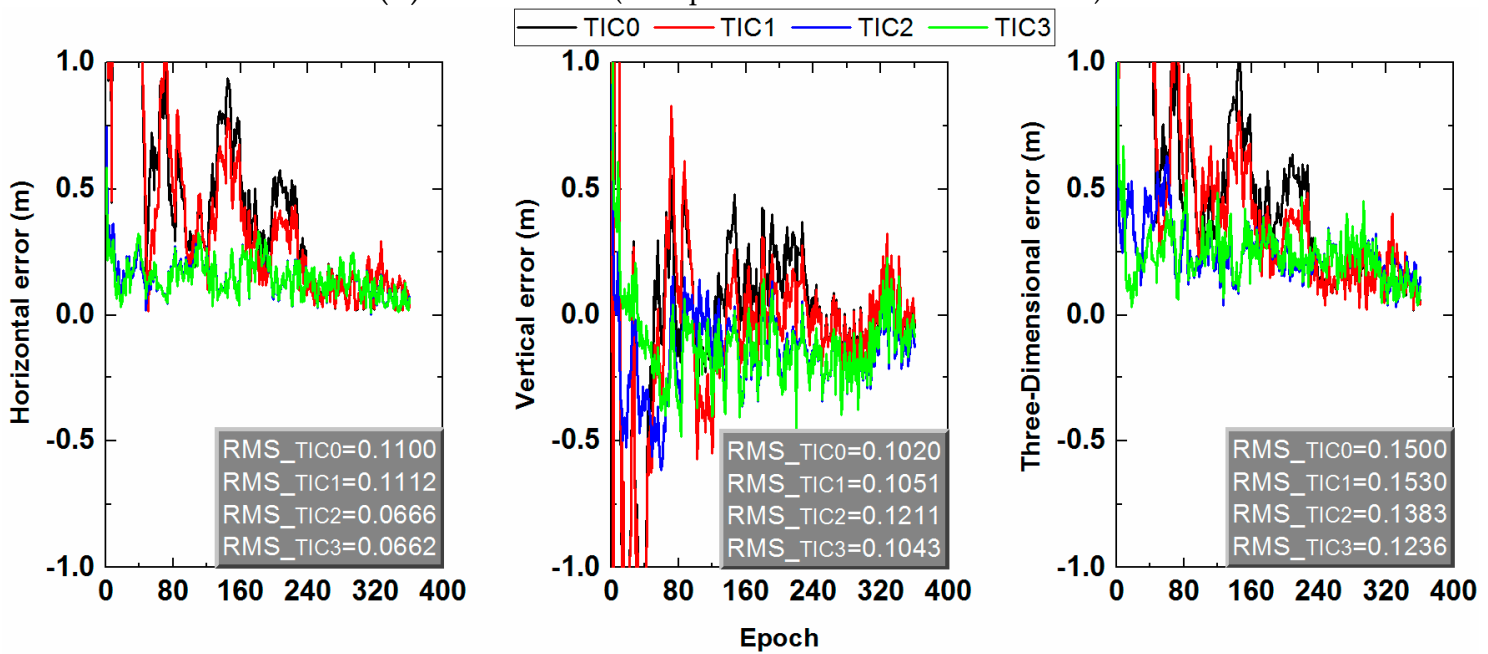

(c) ZECK Station (30 September 2017 3:00:00-5:59:30)

Figure 11. (a) FLRS station, (b) TRO1 station and (c) ZECK station SF PPP coordinate deviation RMS statistics in kinematic mode.

\section{Conclusions}

In this study, we discussed the effects of four methods, including NENE, BILI, BICU, and JUNK, for the percentage of convergence time, the average convergence time and the calculation time of single station of SF TIC2 PPP. The numerical results show that: (1) the percentage of the convergence time of the estimated parameters through the BILI method is the shortest in every condition; and, (2) in the static mode, when the RMS is less than $5 \mathrm{~cm}$, only the percentage of the BILI method calculation exceeds $40 \%$. While in the kinematic mode, when the RMS is less than $15 \mathrm{~cm}$, only the BILI method is more than $60 \%$ and $40 \%$ in the horizontal and vertical component, respectively. Under the other identical thresholds of the RMS, the percentage of the convergence time of the estimated parameters through BILI method is higher than the other three methods; (3) in the static mode, the average convergence time of the estimated parameters through BILI method is reduced by at least $2.2 \%$ when compared to the other three methods and the maximum is shortened by $23.6 \%$; while, in the kinematic mode, they are $1.9 \%$ and $16.6 \%$, respectively; and, (4) for the average computation time of a station, the BILI method has $0.121 \mathrm{~s}$ more than the shortest calculation time in the static mode and $0.038 \mathrm{~s}$ in the kinematic mode. Therefore, we chose the BILI method for calculating the TEC at the required time when using the TIC2 or TIC 3 calculation based on the GIM grid products. 
In order to verify the different constraint methods, a total of 18,720 tests were performed with 78 stations. The experimental results revealed the following findings: (1) the TIC 1 convergence time percentage is slightly higher than the TIC 0 in each convergence time threshold, while the TIC 2 is larger and the TIC3 is the largest. That is to say, the convergence can be accelerated under the constraint conditions; (2) as compared with TIC 0 method, the average convergence time of the TIC1 method is shortened by at least $4.0 \%$ and, at most, $28.9 \%$ in static mode. The TIC 2 method has a larger percentage of shortening, at least up to $16.6 \%$, the maximum up to $88.4 \%$. However, in the vertical component, the TIC1 method is larger than the TIC2 method at the $68 \%$ level. Compared with TIC0, the TIC3 method is shortened by $46.5 \%$ at least and $88.8 \%$ at most. Additionally TIC 3 method is better than TIC1 method and TIC2 method. In kinematic mode, the percentage of time that is shortened after the constraint is less than in static mode. The average convergence time of the TIC1 method is at least $2.1 \%$ shorter than the TIC0 method, and the maximum is shortened by $11.7 \%$. The TIC2 method has a larger percentage of shortening compared to the TIC 1 method, with a minimum of $2.5 \%$ and a maximum of $73.9 \%$. The TIC3 method is superior to the TIC1 method and the TIC2 method, with a minimum of $5.4 \%$ reduction and a maximum reduction of $74.5 \%$ as compared to TIC0; and, (3) through comparative analysis, it is concluded that, the final positioning error of TIC0, TIC1, TIC2 and TIC 3 methods are basically the same, no method is better. After the above analysis and conclusions, under the constraints of atmospheric error products, convergence can be accelerated, and there is no impact on the final accuracy improvement.

Author Contributions: R.W., J.G., N.Z. and Z.L. conceived and designed the experiments; R.W. and Y.Y. performed the experiments and analyzed the data; L.Z. drew pictures; R.W. and Y.W. wrote the paper; all authors reviewed the paper.

Funding: The research was supported by the Fundamental Research Funds for the Central Universities (grant number: 2018BSCXC25), partially sponsored by Postgraduate Research \& Practice Innovation Program of Jiangsu Province (grant number: KYCX18_1952).

Acknowledgments: The authors thank the anonymous reviewer for their valuable comments. Thanks also go to IGS for data and GIM provision. Of course, thanks also to the open-source software GAMP from the team of Feng Zhou of Shandong University of Science and Technology.

Conflicts of Interest: The authors declare no conflict of interest.

\section{References}

1. Zumberge, J.; Heflin, M.; Jefferson, D.; Watkins, M.; Webb, F. Precise point positioning for the efficient and robust analysis of GPS data from large network. J. Geophys. Res. 1997, 102, 5005-5017. [CrossRef]

2. Kouba, J.; Héroux, P. Precise point positioning using IGS orbit and clock products. GPS Solut. 2001, 5, 12-28. [CrossRef]

3. Zhang, X.H.; Andersen, O.B. Surface ice flow velocity and tide retrieval of the Amery ice shelf using precise point positioning. J. Geod. 2006, 80, 171-176. [CrossRef]

4. Choy, S.; Bisnath, S.; Rizos, C. Uncovering common misconceptions in GNSS Precise Point Positioning and its future prospect. GPS Solut. 2017, 21, 13-22. [CrossRef]

5. Bisnath, S.; Gao, Y. Current state of Precise Point Positioning and future prospects and limitations. In Observing Our Changing Earth, Proceedings of the International Association of Geodesy Symposia, Perugia, Italy, 2-13 July 2007; Springer Link: Berlin, Heidelberg, 2009; Volume 133, pp. 615-624.

6. Marques, H.A.; Monico, J.F.G.; Aquino, M. RINEX_HO: Second- and third-order ionospheric corrections for RINEX observation files. GPS Solut. 2011, 15, 305-314. [CrossRef]

7. Banville, S.; Sieradzki, R.; Hoque, M.; Wezka, K.; Hadas, T. On the estimation of higher-order ionospheric effects in precise point positioning. GPS Solut. 2017, 21, 1817-1828. [CrossRef]

8. Odijk, D.; Zhang, B.C.; Khodabandeh, A.; Odolinski, R.; Teunissen, P.J.G. On the estimability of parameters in undifferenced, uncombined GNSS network and PPP-RTK user models by means of S-system theory. J. Geod. 2016, 90, 15-44. [CrossRef]

9. Rovira-Garcia, A.; Juan, J.M.; Sanz, J.; Gonzalez-Casado, G.; Ibanez, D. Accuracy of ionospheric models used in GNSS and SBAS: Methodology and analysis. J. Geod. 2016, 90, 229-240. [CrossRef] 
10. Shi, C.; Gu, S.F.; Lou, Y.D.; Ge, M.R. An improved approach to model ionospheric delays for single-frequency precise point positioning. Adv. Space Res. 2012, 49, 1698-1708. [CrossRef]

11. Lou, Y.D.; Zheng, F.; Gu, S.F.; Wang, C.; Guo, H.L.; Feng, Y.M. Multi-GNSS precise point positioning with raw single-frequency and dual-frequency measurement models. GPS Solut. 2016, 20, 849-862. [CrossRef]

12. Abd Rabbou, M.; El-Shazly, A.; Ahmed, K. Comparative analysis of multi-constellation GNSS single-frequency precise point positioning. Surv. Rev. 2018, 50, 373-382. [CrossRef]

13. Choy, S.; Silcock, D. Single frequency ionosphere-free precise point positioning: A cross-correlation problem? J. Geod. Sci. 2011, 1, 314-323. [CrossRef]

14. Heroux, P.; Gao, Y.; Kouba, J.; Lahaye, F.; Mireault, Y.; Collins, P.; Macleod, K.; Tetreault, P.; Chen, K. Products and applications for precise point positioning-Moving towards real-time. In Proceedings of the ION GNSS 2004, Long Beach, CA, USA, 21-24 September 2004.

15. Hernandez-Pajares, M.; Juan, J.M.; Sanz, J.; Orus, R.; Garcia-Rigo, A.; Feltens, J.; Komjathy, A.; Schaer, S.C.; Krankowski, A. The IGS VTEC maps: A reliable source of ionospheric information since 1998. J. Geod. 2009, 83, 263-275. [CrossRef]

16. Liu, A.; Wang, N.B.; Li, Z.S.; Zhou, K.; Yuan, H. Validation of CAS's final global ionospheric maps during different geomagnetic activities from 2015 to 2017. Results Phys. 2018, 10, 481-486. [CrossRef]

17. Brunini, C.; Van Zele, M.A.; Meza, A.; Gende, M. Quiet and perturbed ionospheric representation according to the electron content from GPS signals. J. Geophys. Res. Space Phys. 2003, 108, 1056. [CrossRef]

18. Bakry El-Arini, M.; Conker, R.S.; Albertson, T.W.; Reagan, J.K.; Klobuchar, J.A.; Doherty, P.H. Comparison of real-time ionospheric algorithms for a GPS Wide-Area Augmentation System (WAAS). Navigation 1994, 41, 393-414. [CrossRef]

19. Chao, Y. Real Time Implementation of the Wide Area Augmentation System for the Global Positioning System with an Emphasis on Ionospheric Modeling. Ph.D. Thesis, Stanford University, Stanford, CA, USA, 1997.

20. Orus, R.; Hernandez-Pajares, M.; Juan, J.M.; Sanz, J. Improvement of global ionospheric VTEC maps by using kriging interpolation technique. J. Atmos. Sol. Terres. Phys. 2005, 67, 1598-1609. [CrossRef]

21. Lanyi, G.E.; Roth, T. A comparison of mapped and measured total ionospheric electron content using Global Positioning System and beacon satellite observations. Radio Sci. 1988, 23, 483-492. [CrossRef]

22. Arikan, F.; Nayir, H.; Sezen, U.; Arikan, O. Estimation of single station interfrequency receiver bias using GPS-TEC. Radio Sci. 2008, 43, RS4004. [CrossRef]

23. Lu, W.J.; Ma, G.Y.; Wang, X.L.; Wan, Q.T.; Li, J.H. Evaluation of ionospheric height assumption for single station GPS-TEC derivation. Adv. Space Res. 2017, 60, 286-294. [CrossRef]

24. Kao, S.; Tu, Y.; Chen, W.; Weng, D.J.; Ji, S.Y. Factors affecting the estimation of GPS receiver instrumental bias. Surv. Rev. 2013, 44, 59-67. [CrossRef]

25. Chen, J.; Huang, L.K.; Liu, L.L.; Wu, P.T.; Qin, X.Y. Applicability analysis of VTEC derived from the sophisticated Klobuchar model in China. ISPRS Int. J. Geo. Inf. 2017, 6, 75. [CrossRef]

26. Liu, X.F.; Yuan, Y.B.; Tan, B.F.; Li, M. Observational analysis of variation characteristics of GPS-based TEC fluctuation over China. ISPRS Int. J. Geo. Inf. 2016, 5, 237. [CrossRef]

27. Niell, A.E. Global mapping functions for the atmosphere delay at radio wavelengths. J. Geophys. Res. 1996, 101, 3227-3246. [CrossRef]

28. Boehm, J.; Moller, G.; Schindelegger, M.; Pain, G.; Weber, R. Development of an improved empirical model for slant delays in the troposphere (GPT2w). GPS Solut. 2006, 19, 433-441. [CrossRef]

29. Niell, A.E. Preliminary evaluation of atmospheric mapping functions based on numerical weather models. Phys. Chem. Earth 2001, 26, 475-480. [CrossRef]

30. Huang, L.K.; Xie, S.F.; Liu, L.L.; Li, J.Y.; Chen, J.; Kang, C.L. SSIEGNOS: A new Asian single site tropospheric correction model. ISPRS Int. J. Geo. Inf. 2017, 6, 20. [CrossRef]

31. Zhang, L.; Yao, Y.B.; Peng, W.J.; Shan, L.L.; He, Y.L.; Kong, J. Real-time global ionospheric map and its application in single-frequency positioning. Sensors 2019, 19, 1138. [CrossRef]

32. Aggrey, J.; Bisnath, S. Improving GNSS PPP convergence: The case of atmospheric-constrained, multi-GNSS PPP-AR. Sensors 2019, 19, 587. [CrossRef]

33. Gao, Z.Z.; Shen, W.B.; Zhang, H.P.; Niu, X.J.; Ge, M.R. Real-time kinematic positioning of INS tightly aided multi-GNSS ionospheric constrained PPP. Sci. Rep. 2016, 6, 30488. [CrossRef] 
34. Zhou, F.; Dong, D.N.; Ge, M.R.; Li, P.; Wickert, J.; Schuh, H. Simultaneous estimation of GLONASS pseudorange inter-frequency biases in precise point positioning using undifferenced and uncombined observations. GPS Solut. 2018, 22, 19. [CrossRef]

35. Zhou, F.; Dong, D.N.; Li, W.W.; Jiang, X.Y.; Wickert, J.; Schuh, H. GAMP: An open-source software of multi-GNSS precise point positioning using undifferenced and uncombined observations. GPS Solut. 2018, 22, 33. [CrossRef]

36. Jayapal, V.; Zain, A.F.M. Interpolation and extrapolation techniques based neural network in estimating the missing ionospheric TEC data. In Proceedings of the Progress in Electromagnetic Research Symposium (PIERS), Shanghai, China, 9-11 August 2016; pp. 695-699.

37. Pang, Z.; Tan, H.; Chen, D. An Improved Low-cost Adaptive Bicubic Interpolation Arithmetic and VLSI Implementation. Acta Autom. Sin. 2013, 39, 407-417. [CrossRef]

38. Keys, R.G. Cubic convolution interpolation for digital image processing. IEEE Trans. Acoust. Speech Signal Process. 1981, 29, 1153-1160. [CrossRef]

39. Dach, R.; Hugentobler, U.; Fridez, P.; Meindl, M. Bernese GPS Software Version 5.0; Astronomical Institute, University of Bern: Bern, Switzerland, 2007.

40. Yun, D.H.; Kee, C. Single-frequency differential GPS accuracy improvement via local area ionospheric time delay model development. Telecommun. Rev. 1999, 9, 33-49.

41. Lwano, S.; Fukuda, Y.; Sato, T.; Tamura, Y.; Matsumoto, K.; Shibuya, K. Long-period tidal factors at Antarctica Syowa Station determined from 10 years of superconducting gravimeter data. J. Geophys. Res. Solid Earth 2005, 110, B10403.

42. Bidikar, B.; Rao, G.S.; Ganesh, L. Sagnac effect and SET error based pseudorange modeling for GPS applications. In Proceedings of the Fourth International Conference on Recent Trends in Computer Science \& Engineering (ICRTCSE 2016), Chennai, India, 29-30 April 2016; Volume 87, pp. 172-177.

43. Han, C.H.; Cai, Z.W. Relativistic effects to the onboard BeiDou satellite clocks. Navig. J. Inst. Navig. 2019, 66, 49-53. [CrossRef]

44. Cai, C.S.; Gong, Y.Z.; Gao, Y.; Kuang, C.L. An approach to speed up single-frequency PPP convergence with quad-constellation GNSS and GIM. Sensors 2017, 17, 1302. [CrossRef]

(C) 2019 by the authors. Licensee MDPI, Basel, Switzerland. This article is an open access article distributed under the terms and conditions of the Creative Commons Attribution (CC BY) license (http://creativecommons.org/licenses/by/4.0/). 